\title{
ELECTORAL COMPETITION UNDER THE THREAT OF POLITICAL UNREST ${ }^{\text {}}$
}

\author{
Matthew Ellman and Leonard Wantchekon \\ A ugust 11, 1999 \\ (Forthcoming, The Quarterly J ournal of Economics)
}

\begin{abstract}
A bstract
We study elections in which one party (the strong party) controls a source of political unrest; e.g., this party could instigate riots if it lost the election. We show that the strong party is more likely to win the election when there is less information about its ability to cause unrest. This is because when the weak party is better informed, it can more reliably prevent political unrest by implementing a "centrist" policy. When there is uncertainty over the credibility of the threat, "posturing" by the strong party leads to platform divergence.
\end{abstract}

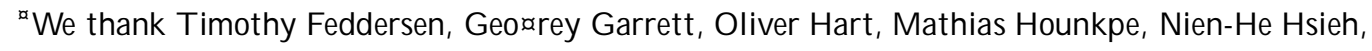
Elena Krasnokutskaya, Eric Maskin, Steve Morris, Roger Myerson, Martin Osborne, Ben Polak, Andrei Shleifer, Christopher Udry, Asher Wolinsky, two anonymous referees and an editor of this journal for comments and suggestions. We are also grateful for helpful comments from seminar participants at U niversity of M ichigan, Harvard University, N ew Y ork U niversity and Yale University. We are responsible for any remaining errors.
} 


\section{INTRODUCTION}

This paper examines how voting and the outcomes of majority rule elections are axected by factors beyond the control of the winning party. We present a model that helps to predict how threats against the electoral process in $\ddagger$ uence: (1) platform choice by political parties, (2) which party wins the election, and (3) the policy outcomes ..nally implemented. In a democracy where the majority winner sets policy, dissatis..ed groups, including groups outside the electoral process, may still be able to interfere with that policy. A losing party may organize a coup; voters may riot; unions may go on strike; investors may take their capital abroad; terrorists and foreign powers may threaten disruption and loss of life; foreign powers may withdraw aid or even impose a trade embargo. We analyze the exect of these non-electoral factors on electoral outcomes.

We consider a majority-rule electoral competition between two political parties with ideal policies lying to either side of the median voter's ideal policy. We allow for only a one-dimensional policy space but the disruption possibility leads to a twodimensional outcome space.

A s evident in the examples given above, the actors threatening to interfere with the winner's policy can be inside or outside the electoral process. We focus on the case where there is only one such actor and where the policy preference of the threatening actor is aligned with one of the political parties. That party's policy proposal faces no threat of disruption and is called the "strong" party. The other party will be called the "weak" party. We will say that the "strong" party is "directly strong" if it controls the unrest itself (e.g., when the threatening actor and the strong party are one and the same and "inside" the political process.) It is "indirectly strong" if the threatening actor is a distinct agent, an "outsider" to the political process. ${ }^{1}$ The distinction between direct and outsider control is important only in sections $\mathrm{V}$ and

\footnotetext{
${ }^{1}$ In this "outsider control" case, the "strength" derives from the fact that the threatening actor has the same ideal point and its threats "support" the strong party's interests.
} 
VI where we allow parties to commit to a platform. ${ }^{2}$

"Outsider control" is the most common case. Examples include terrorist activities by private militias, labor strikes by unions and capital łight by investors responding to high taxes or restrictive regulations. Direct control is applicable when one political party controls the military or has a private militia. For instance, in the 1970 and 1980 elections in Zimbabwe, voters and political parties knew that Robert Mugabe controlled the military and could organize a coup if he lost an election. Under both direct control and outsider control, the threatening actor accepts the winner's policy if it is close enough to its own preferred policy, but otherwise rejects the policy by initiating political unrest or causing disruption.

Our ..rst result is surprising: when parties cannot commit to the policy they will implement upon winning, the "weak party" may bene..t from its own weakness. When the weak party wins, it will always choose policy that is a compromise with the threatening actor (be it a party or an outsider). A winning strong party will always choose to implement its ideal policy: this incurs no risk of interference even under outsider control. However, when the weak party does not know how much compromise is necessary, voters may not trust the weak party to limit the risk of disruption.

O ur second result demonstrates how uncertainty captures distrust: when the threatening party's propensity to interfere is privately known by the strong party, voters may support an extremist "strong party" to avoid the risk of disruption. This is illustrated by EI Salvador's ..rst post civil war election (see Section VII and Wantchekon [1999]).

When political parties can commit to their platforms prior to elections, we ask whether the platforms will converge, and which party will win the election. We ..nd that parties converge to the median voter's ideal point when the threat is minor.

\footnotetext{
${ }^{2} \mathrm{~N}$ ote that there are two reasons why a party might cause disruption: to obtain direct bene.ts of of ce and to shift the policy outcome. In the outsider control case, only the policy shifting reason is valid but our analysis applies equally given the assumption we make.
} 
When the threat is serious, they converge at the strong party's reservation policy, that is, the policy outcome at which the strong party is indixerent between disrupting the political process and accepting the winner's policy proposal. Furthermore, in the case of direct control with a direct bene.t to winning the election, our model predicts that the strong party wins if the threat is serious. This is so because the strong party can oxer a policy that is a little closer to the median voter's ideal point than the weak party can oxer while credibly avoiding the risk of political unrest. The strong party would lose the direct bene.ts from winning if it creates unrest to undo its own policy. Thus, the strong party can credibly promise a more centrist undisrupted policy than can the weak party.

Our model also allows us to predict when platforms will diverge in an election. When there is uncertainty over the credibility of the interference threat, "posturing" by a strong party with private information about the risk of unrest can lead to platform divergence. Such platform divergence occurs because the strong party knows that voters are willing to trade ox policy preference against political unrest.

The paper is organized as follows: Section II describes the basic model, which involves two competing parties that dixer in their ability to interfere in the political process. Section III analyzes the equilibrium behavior of the basic model, assuming that the two parties' costs of political unrest are exogenous and known by everyone. Section IV shows the equilibrium outcome when parties' costs of disrupting the political process are private information. Sections $\mathrm{V}$ and $\mathrm{VI}$ extend the basic model to the case where parties can choose policy platforms before the election. W ith known party costs of disruption, platforms tend to converge. However, reintroducing private information in Section VI, we can explain divergent platforms even when the direct bene.ts from winning the election are arbitrarily large. Section VII discusses four applications of the model. Section VIII concludes, and all proofs are in the A ppendix. 


\section{THE MODEL}

We consider an electoral game involving two political parties and a large number of voters. One set of actors can induce political unrest as a response to electoral defeat. The threat of unrest or "interference" may be controlled by a political party or by an outsider. The game has four stages. First, parties choose platforms. Then, there is an election. After the election, the winner sets a policy. Finally, the losing party or the outsider either accepts that policy or responds with disruptive interference. We will ..rst study the case where parties cannot commit to their platforms (in which case the ..rst stage of the game is irrelevant), and then we will move to the case where they can commit to their platforms.

Preferences. We assume that voters are risk neutral and have single peaked political preferences represented by an ideal point, $\mu 2$ [i 2;2], with constant marginal disutility for deviation from this ideal point. We assume that the median voter denoted $\mathrm{M}$ has an ideal point at $\mu=0$. Furthermore, a voter of type $\mu$ has a ..xed negative payow, i $c_{\mu}$, whenever political unrest takes place.

Under direct control, one of the two parties, $\mathrm{s}$, is strong and earns i $\mathrm{C}_{\mathrm{s}}$ if it initiates political unrest. The other party, $w$, is weak and gains a lower payoo i $c_{w}$ if political unrest occurs $\left(\mathrm{i} \mathrm{C}_{\mathrm{w}}<\mathrm{i} \mathrm{c}_{\mathrm{s}}\right){ }^{3} \mathrm{~W}$ hen unrest is controlled from outside the electoral system, the outsider, denoted $z$; gets a payox i $c_{z}$ by initiating unrest. The weak party and the strong party then get lower payous, i $c_{w}$ and $i c_{s}$, respectively.

Like voters, parties have single peaked policy preferences. The weak party has its ideal point at +2 , while the strong party and the threatening outsider have their ideal points at i $2:^{4}$ We denote by $\mathrm{i}$, the identity of the winning party and by $\mathrm{y}$ its policy proposal. We denote by $r$ the probability of interference by the losing party

\footnotetext{
${ }^{3}$ In the case of a military coup by the strong party, one could argue that i $c_{s}$ would be positive because this party takes power and gets the direct bene.ts of of ce. However we will assume that "interference" generally involves some costs for all parties.

${ }^{4} \mathrm{~T}$ his assumes that no voter is more extreme than either party, but this simpli..cation can easily be removed.
} 
or the outsider. Thus, the outcome of the election can be characterized by the triple: $(y ; r ; i)$.

Payoxs. Players' utility functions depend on (1) the distance between their ideal points and the policy outcomes, (2) the cost of political unrest and (3) the probability of political unrest. The payox for a voter with ideal point $\mu, \mathrm{U}_{\mu}(y ; r ; i)$ is given by

$$
\text { i }\left[(1 ; r) \phi j y \text { i } \mu j+r \phi c_{\mu}\right]:
$$

Political parties have preferences of the same form but they may also value winning per se. That is, we allow for the addition of a bene.t, $R$, to the winning party's payox, conditional on the winner not facing interference. ${ }^{5} \mathrm{~B}$ ut this direct bene..t is irrelevant when parties cannot commit to a platform, so we set $\mathrm{R}=0$ without loss of generality until Section V. Noting that $j y_{i}(i 2) j=2+y$ and $j y i 2 j=2 i \quad y^{6}$ the strong party's payox, $U_{s}(y ; r ; i)$, is given by

$$
\text { i }\left[(1 ; r) \phi\left(y+2 ; R \phi_{s}\right)+r \phi c_{s}\right]
$$

where $\mathrm{I}_{\mathrm{s}}=1$ if $\mathrm{s}$ wins the election and $\mathrm{I}_{\mathrm{s}}=0$ if it loses. Meanwhile, the weak party's payoo, $U_{w}(y ; r ; i)$, is

$$
\text { i }\left[(1 ; r) \phi\left(2 \text {; yi } R \phi l_{w}\right)+r \phi c_{w}\right]:
$$

A gain, $I_{w}=1$ if $w$ wins and $I_{w}=0$ otherwise. For $z$, the payo,$U_{z}(y ; r ; i)$ is

$$
i\left[(1 ; r) \phi(y+2)+r \phi c_{z}\right] .
$$

Note that if there is no unrest, each party is guaranteed a payox of at least $\mathrm{i} 4$; and the median voter is guaranteed a payo of at least $i 2$ : in the extreme case when one party wins the election and implements its ideal point, its payox is R, its opponent's i 4; and the median voter's i 2:

\footnotetext{
${ }^{5}$ To simplify, we assume that payoxs from interference do not depend on which party won.

${ }^{6}$ Note that jy i $($ i 2 ) j $=2+y$ and jy i 2 j $=2$ i y hold for y 2 [i $2 ; 2$ ]. y 2 [i $2 ; 2$ ] can be justi..ed by using the fact that neither party uses dominated strategies.
} 
We assume that (1) political unrest is more costly to the weak party than to the threatening actor, (2) interference by the threatening actor imposes such large costs on all other parties that they prefer any policy to one which always leads to interference. This assumption simpli..es the analysis and is appropriate to major threats such as coups and widespread strikes, terrorist activity and capital $¥$ ight, ${ }^{7}$ and (3) the threatening actor has costs suф ciently low that it interferes with the electoral outcome if the weak party does not compromise towards i 2; That is,

ASSUMPTION A1: $\mathrm{C}_{\mathrm{w}}>4, \mathrm{C}_{\mathrm{s}} 2(0 ; 4)$

ASSUMPTION A1 $1^{0}: c_{w} ; c_{5}>4, c_{z} 2(0 ; 4)$

The..rst part of each assumption captures the fact that the weak and the indirectly strong parties have a vested interest in maintaining peace and in avoiding disruption. The second part captures s or z's incentive to interfere after the election. We further assume that the cost of violence on voters is independent of their ideal points and that political unrest imposes such a large cost on voters that they prefer any policy to one that always leads to political unrest. That is,

\section{ASSUMPTION A2: $8 \mu, c_{\mu}=c, 4:$}

The median voter $M$ is said to be decisive if and only if the strong party $s$ (re spectively the weak party $w$ ) wins whenever $M$ strictly prefers $s$ (respectively $w$ ). Assumption A2 enables us to derive conditions under which the median voter is decisive. We solve for the Subgame Perfect Equilibrium extending the solution concept to Perfect Bayesian Equilibria when private information is present. We rule out non-credible threats by adding the mild assumption that no player follows a weakly dominated strategy. In particular,

ASSUMPTION AA: s, w and z never adopt a weakly dominated strategy.

\footnotetext{
${ }^{7} \mathrm{~A}$ small subset of voters who are not so hurt by the interference is plausible but should not undo our results.
} 
This allows us to use $\mathrm{A} 1$ and $\mathrm{A} 2$ to prove our key lemma showing that the median voter is decisive in the case of direct control, even though the post-electoral outcome has two dimensions, $y$ and $r$. For the case of outsider control ( 1 replacing $A 1^{0}$ ), we need to be sure that $\mathrm{s}$ can always predict what $\mathrm{z}$ will do. We therefore assume throughout that $s$ knows $c_{z}$ and to avoid having $z$ follow a mixed strategy which $s$ cannot predict, we assume that $z$ is peaceful when indixerent:

ASSUMPTION AB: s observes $C_{z}$ and $z$ never creates unrest when indixerent.

The lemma is stated below. In order to prove the decisiveness of the median voter (part ii), we will use the fact that voters anticipate that political unrest never occurs when $\mathrm{s}$ wins the election (part i).

LEMMA 1: Under both direct ( $A 1, A 2$ and $A A)$ and outsider $\left(A 1^{\circ}, A 2, A A\right.$, and $A B$ ) control, (i) $r=0$ at any policy potentially set by $s$; (ii) the median voter is decisive.

The proof of Lemma 1 uses the fact that the utility functions and the costs of political unrest to the players are separable. In Ellman and Wantchekon (1999) we prove the Lemma under less restrictive assumptions on the cost of unrest, $c_{\mu}$.

In the next two sections, we solve for equilibrium when neither party can commit to a platform.

\section{NO PLATFORM COMMITMENT AND NO PRIVATE INFORMATION}

We ..rst describe the outsider control case and brieły explain the direct control case. Suppose that $y$ is the policy chosen at stage 3 by the majority winner. At stage 4 , the outsider, $z$, initiates political unrest if i $C_{z}>$ i 2 i y. We de.ne $y^{\prime} C_{z}$ i 2 so that the two payous are equated at $y=y$. Given A ssumption $A B, z$ 's best response is to initiate political unrest if $y>\nabla$ and not to initiate political unrest if $y \cdot g .{ }^{8}$

\footnotetext{
${ }^{8} \mathrm{~N}$ ote that there is only one threatening actor: neither w nor $\mathrm{S}$ "interferes" by assumption $\mathrm{A} \mathrm{l}^{0}$.
} 
When $\mathrm{w}$ wins and chooses $\mathrm{y}$ at stage $3, \mathrm{w}$ anticipates a payox of $\mathrm{i} \mathrm{C}_{\mathrm{w}}$ from setting $y>8$ and $y_{\text {i }} 2$ from setting $y$. $\nabla$. It is optimal for $w$ to avoid unrest with the least possible policy compromise by setting $y=y$ : Using ${ }^{\alpha}$ to identify w's equilibrium strategies, we have $y_{w}^{a}=y$. In contrast, when s wins and chooses the policy, s can choose its ideal point. Since $s$ and $z$ have the same ideal point, $z$ will not cause unrest against this policy. Thus, the policy outcome is $y_{s}=i 2$ if $s$ wins and $y_{w}=\nabla$ if $w$ wins. At stage 2, voters anticipate these electoral outcomes. By $A 1^{0}, \nabla$ is closer to the median voter's ideal point than i 2 , so the median voter prefers $w$ to win. So, by Lemma 1, w wins. The policy implemented is $\mathrm{y}$ and the probability of unrest, $r=0$. Note that there is no risk of unrest because $\mathrm{w}$ dislikes unrest and is perfectly aware how much compromise is required.

The result is equally true under A 1 (the direct control case). We only need to note that $\mathrm{s}$ still sets $\mathrm{y}_{\mathrm{s}}=\mathrm{i} 2$ at stage 3 because this guarantees it its highest possible payor. The outcome is exactly as above, except that $y=c_{s}$ i 2 . We will refer to $y$ as the reservation policy of the threatening actor. It is the minimal policy compromise which w (or w and s) must make to prevent s (or z) from causing trouble.

PROPOSITION 1. Under A 1 (respectively $A 1^{0}$ ), there is a unique Subgame Perfect Equilibrium: the weak party wins the election, implements the strong party's (respectively, threatening actor's) reservation policy, and there is no political unrest, i.e., $\mathrm{i}=\mathrm{w} ; \mathrm{y}_{\mathrm{w}}^{\mathrm{a}}=\mathrm{g}^{\prime} \mathrm{c}_{\mathrm{s}} \mathrm{i} 2$ (respectively $c_{z} \mathrm{i} 2$ ) and $r=0$ :

Proposition 1 shows that the threat of collapse in the political process can prevent the winner from "taking all" even in a majoritarian system. Under complete information, the median voter prefers the weak party because she anticipates that the weak party will be moderated toward her ideal point by the fear of political unrest. ${ }^{9}$

\footnotetext{
${ }^{9} \mathrm{~T}$ his is an example of (ex post) moderation of policy outcomes. The moderation is independent of voter behavior in contrast to A lesina and Rosenthal (1995) in which moderation arises because voters select a president and then select an opposing group of legislators. We also note that our result will apply even for a multi-party election so long as that the threat of unrest forces the winning party to moderate its policy proposal.
} 
The median voter is decisive in the one-dimensional context where political unrest never occurs because preferences are single peaked and identical up to translations of the ideal point. If the strong party or threatening outsider could credibly commit against creating unrest after the election, the median voter would anticipate that, if elected, the weak party would implement its ideal policy. In this case, the median voter would vote for the strong party. Thus, the strong party's electoral loss comes from its inability to commit not to interfere after the election.

Robustness: We note two possibilities which reverse this surprising result. Were $c_{s}<0$, w would be unable to compromise enough to avoid political unrest and voters would vote for $s$ instead of $w$. Secondly, as mentioned above, one might want to consider the case in which the order of stages 3 and 4 is reversed (for example, if policy choice becomes ..xed only some time after the election and the electoral winner can neutralize the threat of $\mathrm{s}$ or $\mathrm{z}$ in this interim since the interference decision must be made before the policy choice is observed) ${ }^{10}$. Unrest must pre-empt "disarmament." Now that the electoral winner sets the policy after the unrest decision has been made, $\mathrm{w}$ will set $\mathrm{y}=2$ at stage 4 . Anticipating this, $\mathrm{s}$ (or $\mathrm{z}$ ) would create unrest as soon as w wins (before being "disarmed"). Voters then prefer to vote for $\mathrm{s}$ rather than w because $y=2$ is better than $r=1$. In this case, w suxers from being unable to commit to a policy and w would bene.t. when platform commitment becomes possible at stage $1 .^{11}$ We focus on the timing stated in section II because a party's policy plan often becomes clear before the party is able to neutralize interference threats. However, the alternative timing is an interesting avenue for further research.

Proposition 1 can help make sense of electoral outcomes in new democracies where the most "peaceful" party or the party with the weakest military support has been elected. For instance, in Chile in 1990, Patricio A Iwin's Center-Left coalition won against Hernán Büchi's strong right-wing party which had close ties to the armed

\footnotetext{
${ }^{10}$ Sometimes militias can be disarmed and new legislation can constrain unions or prevent capital ‡ight.

${ }^{11} \mathrm{~T}$ hanks to Oliver Hart for suggesting further investigation of this commitment issue.
} 
forces. U pon winning, A Iwin implemented relatively conservative economic policies and continued the market reforms started under General Pinochet. We suggest that sixteen years of Pinochet made his party's reservation policy relatively predictable and that this policy compromise was necessary to prevent a military coup. ${ }^{12}$ For this reason voters could trust Alwin's party to compromise enough to avoid a coup. As we show in the next section, when the reservation policy is private information, the weak party may lose because voters know that it would risk causing unrest.

\section{NO PLATFORM COMMITMENT AND THE STRONG PARTY HAS PRIVATE INFORMATION.}

In this section, we allow the strong party to have private information over the ability of the threatening actor to disrupt the political process. We show that the strong party may win because of people's fear of such disruption. For the direct control case, it is assumed that the strong party alone knows the true value of $c_{s}$ and hence its reservation policy, $y$. This assumption makes good sense when $c_{s}$ is reinterpreted as the strong party's subjective expectation (at stage 4 ) of its cost from interference. The strong party chooses whether or not to initiate political unrest based on this subjective expectation.

For the case of outsider control, we have to assume that the outsider shares its information with the strong party, that is to say, only s and $z$ know the true value of $c_{z}$ and hence $y$. There is no dixerence between the results under direct control and outsider control so we simply describe the case of direct control. In order to simplify the analysis, we assume that

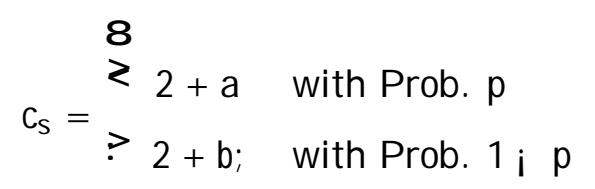

\footnotetext{
${ }^{12}$ M ore recently (November 1998), the Chilean government, particularly its socialist foreign minister, strongly supported $\mathrm{P}$ inochet in his attempt to avoid extradition from England to Spain where he would face charges of human rights violations during his presidency.
} 
where $f a ; b g ~ 2[i 2 ; 2]$. Thus, $\nabla=a$, with probability $p$, and that $\nabla=b$, with probability $1 \mathrm{i}$ p. ${ }^{13}$ In order to focus our analysis on the case where all types of the strong party have reservation policies relatively close to their ideal point of $; 2$, we assume that the "softer" type of the strong party has its reservation policy, b, located to the left of the median voter. That is,

ASSUMPTION 3: ; $2 \cdot a<b<0$ :

The probability of political unrest if $w$ is elected is now given by,

$$
r\left(y_{w}\right)=\begin{array}{ll}
0 & \text { if } y_{w} 2[i 2 ; b] \\
p & \text { if } y_{w} 2[a ; b] \\
1 & \text { if } y_{w} 2[b ; 2]:
\end{array}
$$

De.ne $Y_{w}^{a}{ }^{\prime} \operatorname{argmax} f_{j} ; j 2$ i yj $(1 ; r(y))$ i $c_{w} \phi r(y) g$ and $y_{w}^{a} 2 Y_{w}^{a}$. We claim that $Y_{w}^{a}=f a ; b g:$ To prove this claim, note that any policy y $2(b, 2]$ leads to a payox of $i C_{w}$ and is strictly dominated by $y=a$. This is due to the fact that $y=a$ gives a payox of at least i $4, \quad i c_{w}$. Similarly, y $2(a ; b)$ is strictly dominated by $y=b$ and y 2 [i $2 ; a)$ is strictly dominated by $y=a$.

Let $r^{a}=r\left(y_{w}^{a}\right)$ and $r^{e}$ denote the equilibrium probability of political unrest. We show that when $w$ wins the election, $r^{e}=r^{\star}$. W hen $w$ wins, $w$ trade-ox policy against risk of political unrest. We de..ne by $b_{w}$ the cost of unrest at which $w$ is indixerent between choosing a "safe" policy, $y=a$ and a "risky" policy $y=b$. Proposition 2 presents a suф cient condition for the occurrence of political unrest in equilibrium and proposition 3 describes the electoral outcomes. Proposition 2 has two parts: 2(i) points out that if $w$ wins, the risk of unrest is a decreasing step function of $c_{w}$. 2(ii) points out that even if $w$ risks to cause political unrest, the equilibrium risk of unres is wh $\mathrm{n} \mathrm{c}_{0}$ is suф ciently large. This is because voters will then vote for $\mathrm{s}$ which always sets $y=i 2$ so that $r=0$. We de. ne by $c_{0}$ the cost of unrest at which the median voter would switch from voting for $w(a t y=b$ and $r=p$ ) to voting for $s$.

\footnotetext{
${ }^{13} \mathrm{~F}$ or an analysis of the continuous types case, see ElIman and Wantchekon [1999].
} 
DEFINITION 2: $\epsilon_{0} \cdot \frac{2+b(1 ; p)}{p}$ and $\hat{c}_{w} \cdot \frac{(2 i a)+\left(b_{i} 2\right)(1 ; p)}{p}$ :

PROPOSITION 2: (i) When the weak party wins, the probability of political unrest, $r^{x}=p$ if $c_{w} \cdot c_{w}$ and $r^{x}=0$ as $c_{w}, c_{w}$. (ii) Furthermore, $r^{e}=r^{\not x}$ for $c_{0}<b_{0}$ and $r^{e}=0$ for $c_{0}>b_{0}$.

When the cost of political unrest for the weak party is sul ciently large, that is if $c_{w}, C_{w}$, then the weak party will win the election by credibly promising to set $y_{w}=a$; leading to $r^{\not a}=0$ (and $r^{e}=r^{\not a}=0$ ). When $c_{w}<c_{w}$, the weak party will set $y_{w}>a$ : This leads to a positive probability of interference when the weak party wins, $r^{x}>0$. As a result, if $c_{w}<c_{w}$, and $c_{0}<c_{0}$, then the weak party wins. Otherwise, the strong party wins. When $c_{0}=c_{0}$ each party wins with probability $\frac{1}{2}$. For the sake of emphasis, we state the corollary as a proposition:

PROPOSITION 3: The strong party wins when both $c_{w}<\hat{\epsilon}_{w}$ and $c_{0}>\hat{c}_{0}$.

The result shows that if $c_{w}$ is suc ciently large, the weak party never risks causing political unrest and will always win exactly as in the Proposition 1. If $c_{0}$ is small, the median voter is not overly concerned by political unrest. As a result, the median voter will vote for the weak party, even though this choice can lead to political unrest. So for the strong party to win, $c_{0}$ must be large relative to $c_{w}$.

The strong party has an incentive to scare voters (make them feel that $c_{0}$ is large) but also to obfuscate its willingness to create unrest. The uncertainty surrounding its own (or the threatening actor's) militancy creates an atmosphere of insecurity if $c_{w}$ is suф ciently small that voters believe $w$ will then be willing to risk unrest. This compels voters to lean toward the strong party if they believe that $c_{0}, \hat{c}_{0}$.

Figure I presents the equilibrium probability of unrest $r^{\not}$ as a function of $c_{w}$.

Insert Figure I here

Proposition 3 refects on electoral behavior in the ..rst democratic elections of a country trying to move forward after a period of civil war. For instance, in Liberia 
in 1997, restoration of civil order was the main motive behind the massive vote for the former warlord, Charles Taylor. The same can be said about ARENA's victory in the 1994 presidential elections in EI Salvador (see Section VII). Even in Western democracies faced with serious outside challenges (such as France in 1958) or the threat of internal collapse (Weimar in the 1930s), concerns about the survival of the democratic process may lead the electorate to prefer politicians who have strong ties to the armed forces and can enforce some form of civil order. The rise of fascism or military-style government in some Western democracies before and immediately after the Second World War can be seen as cases where $c_{0}>\hat{c}_{0}$ led to the electoral victory of a strong party.

\section{PLATFORM COMMITMENT AND NO PRIVATE INFORMATION}

In Sections III and IV above, parties were unable to commit to a policy platform. Voting was determined by the parties' ideal points, and the distribution of the threatening actor's reservation policy. Here and in the next section, we assume that while parties cannot commit against initiating political unrest, they can commit to a policy platform. Platform commitment in this case means the winning party will implement the policy proposed in its campaign platform, as long as there is no political unrest. This assumption is more plausible for stable countries such as the U nited K ingdom, Sweden, N orway and Chile since the 1980s.

In order to motivate platform commitment, we argue that in stable democracies, repeated elections allow parties to try to build a reputation for honoring their campaign promises (see Alesina [1988]). For the case of directly controlled threats, we further argue that it is harder to build a reputation for creating unrest. ${ }^{14}$ Alternatively, we can assume that, while choice of party leader provides a credible commitment to

\footnotetext{
${ }^{14} \mathrm{~T}$ he winner of an election in a stable democracy might be better controlled than the loser. For instance, an executive who violates the constitution can be impeached, while an opposition leader who breaks the law might have less to lose.
} 
the policy platform represented by the leader's speci..c ideology, either someone else controls the disruption decision or the leader's speci..c willingness to disrupt is not observable to the voters and the weak party.

We de.ne by $x_{s}$ and $x_{w}$, the strong party and the weak party's platforms. There are two stages of backward induction left to be solved. Even after parties choose their platforms, voters have to anticipate how the strong party would respond if the weak party won the election. Additionally, the parties choose their platforms in anticipation of the electoral and political outcomes that will follow. Now that policy commitment is possible before the election, the direct bene..t from winning the election, $\mathrm{R}$, cannot be "normalized" to 0 . We denote the probability that $\mathrm{s}$ wins by $1 / 4\left(x_{s} ; x_{w}\right)^{\prime} \operatorname{Pr}\left(i=s j x_{s} ; x_{w}\right)$ :

For simplicity, we focus on the outsider control case (assumption $A 1^{0}$ ) and brieły describe the insider control case afterwards. ${ }^{15}$ Since there is no private information in this section, the reservation policy of the outsider, $\mathrm{y}^{\prime} \mathrm{C}_{\mathrm{z}} \mathrm{i} 2$ is known by all the players. We ..nd that the equilibrium platforms converge at $\min (0 ; \mathrm{y}){ }^{16}$

PROPOSITION 4: Under outsider control of political unrest with no private information, party platforms converge at $\min (0 ; \boldsymbol{y})$ : There is no political unrest, and either party may win the election.

Proposition 4 shows that in an environment where parties can commit to their platforms, we should observe more platform convergence. The result is driven by the fact that both parties can now credibly make enough policy compromise in order to win the election, in contrast to the no-commitment case (section III) where only the weak party can make any credible policy compromise. Under direct control of political unrest, platform convergence still occurs at $\min (0 ; y)$ only now, for the case where $y<0$, the strong party always wins in equilibrium. This is because the strong

\footnotetext{
${ }^{15} \mathrm{~A}$ s mentioned before, we assume that $z$, the outsider, has an ideal point of $\mathrm{i} 2$, but a less extreme outsider would give similar results.

${ }^{16} \mathrm{~T}$ his is a version of the well known median voter theorem. As Shepsle [1991] shows, the theorem does not hold if the election involves more than two parties.
} 
party can deviate to $y+$ " for " < R and pick up votes whereas the weak party cannot win with such a deviation because voters know that s would initiate political unrest against $\mathrm{y}=\mathrm{x}_{\mathrm{w}}=\mathrm{y}+{ }^{.17}$

Our results help explain platform choices in the 1990 Chilean elections mentioned above, in which the two candidates adopted essentially the same platform on the main policy issues, especially tax reform. The same logic applies to the 1992 and 1995 elections in Sweden, where increased capital mobility owing to liberalization and integration of international capital markets led social democrats and conservatives to converge toward ..scal discipline and less generous welfare and wage policies (see Moses (1994) for a description of this "ideological abdication" of the Swedish social democrats). A s the next section shows, when voters are ignorant of the risks of capital ¥ight or other forms of disruption, such "ideological abdication" becomes less likely and platform divergence will occur.

\section{PLATFORM COMMITMENT WHEN THE STRONG PARTY HAS PRIVATE INFORMATION}

In this section we show that the strong and weak parties may choose divergent policy positions. This is in contrast to the well-known result that platform commitment leads to convergence. Roemer [1994] and Calvert [1985] have shown that incomplete information over voter preferences can explain some polarization. However, they point out that convergence of equilibrium platforms is a relatively robust result when parties value winning per se $(R>0)$, and uncertainty about the median voter's location is not great. In the case of outsider control, we derive a strong polarization result which holds even when the bene.t from winning is arbitrarily large and voter preferences are known. While other explanations of polarization are compelling in other situations, our novel result has a useful predictive power whenever key factors threatening some form of unrest can be discerned. For the sake of clarity, we continue to focus on the more plausible case of outsider control. We explain how our results

\footnotetext{
${ }^{17} \mathrm{~T}$ he proof of this result is available upon request.
} 
change for the "insider" control case at the end.

Parties can commit to their platforms as in the previous section but now the level of intransigence of the outsider is imperfectly observed by the weak party and the voters. We show that polarization arises on account of posturing by the (indirectly) strong party. Even when the outsider is relatively weak, the strong party can pretend to know that the outsider is militant in the hope that voters will be fooled. The strong party signals this claim of militancy by adopting an extremist platform (it is less willing to converge when the outsider threat really is militant). When the voters are swayed by this posturing, they accept the strong party's extreme platform. The weak party will not converge to that platform because it thinks that voters may be less afraid of the strong party than the strong party had hoped. The weak party then gains from having oxered a platform closer to its own ideal point.

As section III, we model the uncertainty over the threatening actor's intransigence by allowing $C_{z}$ and therefore the outsider's reservation policy to be private information. We assume that $z$ can be one of two types: $z_{1}$ is militant and has $z=a ; z_{2}$ is weaker and has $\mathrm{y}=\mathrm{b}$ Only $\mathrm{s}$ (and $\mathrm{z}$ ) are assumed to learn the actual realization of $c_{z}$ before the election is held. Since we are in the outsider control case, we have assumption $A 1^{0}$ with stochastic $C_{z}$. Note that while $C_{s}$ is ..xed for this case, we write $s=s_{1}$ when $s$ learns that $z$ is "militant" (has low cost $c_{z}=a+2$ ) and $s=s_{2}$ when $z$ is "soft."

If voters are suc ciently afraid of a militant threat ( $p$ is high and or $c_{0}$ is high), $s_{1}$ and $s_{2}$ might pool on $x \cdot a$ and always win so that $w$ might as well converge. The following assumption helps to rule out the pooling equilibria which allow convergence through voters' fear,

$$
\text { ASSUMPTION 4: } p<p^{\prime} \frac{b_{i} a}{b+c_{0}} \text { : }
$$

If the weak party is too averse to unrest (high $\mathrm{c}_{\mathrm{w}}$ ), it may avoid all risk of unrest by oxering only the highest no risk platform, $x=a$. Assumption $A 5$ is used to ensure that the weak party is willing to risk political unrest by not converging to the militant 
outsider's reservation policy, $a$, in the hope that $z$ is only type $z_{2}$. Note that this assumption gets monotonically weaker as $\mathrm{R}$ increases and is reasonable even for $\mathrm{R}$ close to 0.

$$
\text { ASSUMPTION 5: } \mathrm{c}_{\mathrm{w}}<\mathrm{c}_{0}+2+{ }^{3} \frac{\mathrm{c}_{0 i} 2^{\prime}}{\mathrm{b}+2} \mathrm{R}
$$

We can now prove that platforms must diverge and that this divergence prediction is robust to an arbitrarily large direct bene.t of winning. Formally, we have:

PROPOSITION 5: Under outsider control of political unrest, all PBE (in undominated strategies) exhibit platform divergence of at least $b_{i} a$, a fraction no less than min $p \Phi_{\frac{R R}{2 R+b+2}} ; 1$ i $p$ of the time. In particular, this divergence is robust to arbitrarily large $R$.

The proof (see Appendix) shows that, given our assumptions, $\mathrm{s}$ always takes an extremist position when $s$ knows that $z$ is militant (a policy to the right of a would lead to unrest with probability 1). Furthermore, in equilibrium, w (and perhaps $s$ when aware that $z$ is relatively soft) will move to platform bwith probability bounded away from 0 . This is explained in the proof of Propostion 5 (see A ppendix).

The equilibrium in which $s_{1}$ and $s_{2}$ pool at a while $w$ oxers $b$ and always wins is one of many which cannot arise in the case of direct control. This is so because $\mathrm{S}_{2}$ wants to win and can achieve this goal by oxering $\mathrm{b}+$ " when s controls unrest directly. In the case of direct control, the equilibria can be pinned down more tightly. Unfortunately, when R ! 1 , we cannot rule out divergence so easily as explained below.

The case of direct control: Platform divergence can also occur when the strong party directly controls political unrest. For instance, for arbitrarily large $R$, there exists a Perfect Bayesian Equilibrium in which the stronger type of the strong party chooses $x_{S_{1}}=a$, the weaker type of strong party randomizes between $x_{s_{2}}=a$ and $\mathrm{x}_{\mathrm{s}_{2}}=\mathrm{b}$; and the weak party chooses $\mathrm{x}_{\mathrm{w}}=\mathrm{b}$ In this equilibrium, the weak party 
sometimes wins when the platforms diverge but always loses when the platforms converge at $b$ :

However, we can no longer rule out the existence of convergent equilibria as R! 1 . The problem is that $s_{1}$ can now oxer $x$ to the right of a because $s_{1}$ will not revolt against itself for any $x<a+R$ even though it revolts against $w$ for any $x>a \cdot{ }^{18} A s$ $R$ ! $1, a+R$ ! 1 too, so this upper bound on $s_{1}$ 's platform becomes too high to guarantee divergence. Even without this, divergence can arise as a result of private information about the strength of a threat. We now use the model to help understand platform divergence under the threat of disruption without worrying exactly how much control the strong party has over that threat.

B efore we turn to some applications of the model, we present a summary table of the equilibrium policies and outcomes discussed in Sections III-VI.

Insert Table I here

\section{APPLICATIONS}

\section{A. Platform Divergence:}

G reat B ritain, 1974. A central question in the February 1974 elections in Great Britain was: "who could control the unions?" The Labour party presented itself as the party most capable of negotiating an end to serious labor disruption. On the other hand, the Conservative Party and the incumbent prime minister E dward Heath wanted a mandate to ..ght inłation and union militancy by limiting wage increases (Butler and K avanagh [1974], p. 265). A ccording to B utler and K avanagh [1974], the electorate was ambivalent about the unions. The median voter appeared to favor the Conservative Party which could "stand up to the unions which push for large wage claims", yet the median voter did not want "the inconvenience which would attend dispute" (p. 256). In the election, the Labour Party narrowly won by promoting a pact with the unions.

\footnotetext{
${ }^{18} \mathrm{~T}$ his is because when $\mathrm{S}$ wins, it stands to lose the political bene.t $\mathrm{R}$ which is contingent on winning power without resorting to extra-political means.
} 
The evidence compiled by Dorfman [1978] and Butler et al. [1974] suggests that public ambivalence regarding the unions resulted in a platform divergence between the two parties on the election's main issue: how to ..ght in $¥$ ation. W hile the Conservatives stressed the need to control wages, Labour pressed for price controls and limits on pro..ts (Butler et al., p. 55). Our model ${ }^{19}$ provides the rationale for this platform divergence between the two parties. B ecause Labour thought that voters were fearful enough of disruptive strikes, it had no incentive to adopt a moderate position. In contrast, the Conservatives hoped that voters would doubt the threat of strikes, and showed no leniency towards the unions by con..rming their uncompromising position on controlling wage increases (Butler et al., p. 98).

Taiwan, 1996. The 1996 presidential election in Taiwan took place, not under the pressure of domestic violence, but under the pressure of an external power. The main candidates were Lee Teng-hui from the K uo M in Tan (K MT), Peng Ming-min from the Democratic Progressive Party (DPP) and Lin Yang-kang from the New Party (NP). Prior to the election, China staged a nine-month military campaign with the clear intent of threatening and intimidating Taiwan's electorate and to stop its move towards independence. However, while the New Party maintained its antiindependence platform, the KMT and the DPP grew more de..ant of China in light of the threats ${ }^{20}$. Both the KMT and the DPP shifted their campaign platforms in favor of more pro-independence policies. Proposition 5 suggests that such platform polarization is the result of voters' uncertainty about the real intentions of the "outsider,"

\footnotetext{
${ }^{19} \mathrm{We}$ use the outsider control case. The following evidence shows that the unions were not fully controlled by the Labour Party. On February 17, 1974, Labour Party leader Harold W ilson, declared the creation of a "social contract" with the union leadership. The following day, however, the leader of the Trade Unions Council, denied having reached any such an agreement (Butler et al., p. 98). In fact, W ilson was referring to the 1973 agreement between Labour and the unions which "provided that, in return to various social policies and the repeal of the Industrial Relations Act, the unions would show voluntary restraint" (p. 55).

${ }^{20}$ See Newsweek, A pril 1, 1996. A lso, Financial Times March 8, 1996 wrote: "Beijing Plays to Weaken Lee's Hand: But the R eaction Has Been De..ant." p.33.
} 
the Chinese government. ${ }^{21}$

B. Electoral Victory of an Extremist and "Strong" Party.

EI Salvador, 1994. In the 1994 presidential election in El Salvador, the issue of land reform was the most polarizing and the most important. Land reform was discussed in the peace accords between the FMLN and ARENA but at the time of the 1994 election there was still much uncertainty as to how the issue would be addressed (Stahler-Stolk [1995]). According to a 1994 survey, 51 percent of the rural population had no land, and 2.9 percent of the landowners held 46 percent of the land (Montgomery [1995]). The peasants had consistently and unequivocally favored a comprehensive land reform policy (see M ontgomery [1995] and Stahler-Stolk [1995]). In light of this evidence, we conclude that the median voter in rural areas was a landless or near-landless peasant who favored land reform. Nonetheless, in the 1994 election this voter preferred ARENA, a party opposed to land reform.

Given that uncertainty over the implementation of the peace accords was the deciding factor in the peasants' decision to support ARENA, voters must have perceived violence under an ARENA government to be less likely than violence under an F MLN government (i.e. ARENA is the strong party and there is a risk of violence if the F M LN wins.) A ccording to 1994 polls, a plurality of voters (31.1 percent) thought the peace accords would be implemented if ARENA were elected and 65.6 percent of the electorate believed that this party was backed by the military (Instituto Universitario de Opinión Pública [1994]). E ven some top F M LN oł cials thought that a victory by their party could endanger the country's stability (V ickers and Spence [1994]). From 1992 to 1994, six top-ranked FM LN leaders were assassinated by right-wing militias. In this environment, rural poor voters believed that F MLN victory would jeopardize the peace accords and lead to a collapse of the democratic process. These concerns about stability and order $\left(c_{0}>b_{0}\right.$ ) led them to prefer ARENA, even though ARENA would implement policies that hurt their interests regarding land reform as arises in the model when $\mathrm{c}_{0}<\mathrm{c}_{0}$.

\footnotetext{
${ }^{21}$ See Wantchekon and Lam [1996] for more details.
} 
Our model suggests that as threats of violence become less of an issue $\left(c_{0}<b_{0}\right)$, ARENA should lose its decisive advantage vis-à-vis the FMLN and the political process should become more competitive. Consistent with our analysis is the outcome of the March 1997 congressional elections in the country. The FMLN won $32.1 \%$ of the vote, as compared to $33.3 \%$ for ARENA. In the mayoral elections, the FMLN more than quadrupled the number of municipalities under its control (54), including the city of San Salvador and its suburbs where more than one-..fth of the country's population lives.

A competing explanation for the F M LN's semi-victory could be a possible backlash against "Washington consensus" policies. But this explanation would not be valid since the country enjoyed a remarkable 4 percent growth rate from 1996 to 1997 despite or because of those policies. In other words, the fact that the ARENA lost the 1997 parliamentary and municipal elections in spite of an excellent economic record con..rms our thesis: (1) the threat of violence was the decisive factor in ARENA's 1994 victory and (2) after the implementation of the peace accords, as the threat declined, a large proportion of the electorate would vote for the $F M L N$ and against the ARENA.

Liberia, 1997. The 1997 presidential elections in Liberia took place after 8 years of civil war that killed over 200, 000 people and destroyed most of the economic infrastructure of the country. The two major candidates were the former World B ank economist Ellen J ohnson Sirleaf and the former warlord, Charles Taylor. Throughout the pre-electoral campaign, Taylor presented himself as the candidate who holds the key for stability and peace. In order to signal to voters what might happen if he were to lose the elections, he threatened the election commission with large scale violence if the election were postponed. These threats and concerns for stability and security became the decisive factor in the electoral outcome. According to a J uly 1997 survey "voters wanted to put end to the war and to elect a strong leader who can maintain itself in of ce."(E conomist, J uly 26, 1997). In the end, nearly $75 \%$ of the electorate preferred Taylor over Sirleaf. Proposition 3 and the empirical evidence suggest that 
Liberians voted in such a great number for Taylor because they were convinced that a new civil war will break out if they were to vote against him. In other words, the outcome of the 1997 elections in Liberia was the result of a strategic move by the electorate to put power in "strong" hands in order to secure peace and security.

\section{CONCLUSION}

This paper analyzes electoral incentives and outcomes when parties face threats of political unrest. We ..nd that without platform commitment, the weaker party is moderated towards the center and wins the election. But when the risk of disruption is privately known by the strong party, the strong party becomes more likely to win as voter fear of disruption grows. With platform commitment and no private information, platform convergence occurs and either party can win unless (1) the strong party directly controls the threat and (2) the threat is serious. In that case, the strong party always wins on the convergent policy. Finally, when the strong party has private information, we predict platform divergence as a result of signalling. When the threat is controlled by an outsider, this divergence is robust to arbitrarily large direct bene.ts of o\$ ce. The equilibrium strategies of parties depend on the cost of political unrest to voters only when the threat is private information.

We have illustrated the main results of the model with the cases of the United Kingdom, Taiwan, El Salvador and Liberia. For instance, in the 1994 Presidential elections in EI Salvador, peasants who favored land reform voted strategically for a party opposed to this reform in order to minimize the risk of post-election violence. In the 1974 parliamentary election in the United Kingdom, Labour took a high-wage position, hoping that voters would believe this redistribution to be necessary to avoid further strikes. Meanwhile, the Conservatives took a divergent position hoping that voters would doubt the credibility of the strike threats. The recent convergence of the Labour and Conservative Parties under B lair's leadership coincides with a weakening of union power in a manner not inconsistent with our model. 


\section{APPENDIX}

N otation: When the letter $\mathrm{j}$ denotes party $\mathrm{s}$ (respectively, w), i j will denote party $\mathbf{w}$ (respectively, s). Recall that $\mathrm{i}$ denotes the winner of the election. We will write sM w (respectively, $\mathrm{s} \mu \mathrm{w}$ ) to denote "the median voter (respectively, voter $\mu$ ) strictly prefers s to w." We will write "+"" when we want to suppress the phrase, "for suф ciently small, positive "."

For sections $\mathrm{V}$ and $\mathrm{VI}, 1 / 4\left(\mathrm{X}_{\mathrm{s}} ; \mathrm{X}_{\mathrm{w}}\right)$ is the probability that $\mathrm{s}$ wins the election when $\mathrm{S}$ and $\mathrm{w}$ have committed to that pair of platforms. $\mathrm{X}_{\mathrm{S}}$ and $\mathrm{X}_{\mathrm{w}}$ denote the supports for $\mathrm{s}$ and w's strategies; for section $\mathrm{VI}, \mathrm{X}_{1}, \mathrm{X}_{2}$ are the supports for $\mathrm{s}$ when $\mathrm{s}=\mathrm{S}_{1}$, $S=s_{2}$ respectively. Recall that for the outsider control case, $s=s_{1}$ implies that $(s$ knows that) $z$ is militant and $s=s_{2}$ implies that ( $s$ knows that) $z$ is soft. Denote by ', the common posterior weight on $s=s_{1}$ in the beliefs of voters and $w$ after observing $x_{s}$.

\section{Proof of Lemma 1}

We de..ne $y$ to be the policy implemented by the winning party, and $x$ to be a pre-electoral platform. We also de..ne by $\mathrm{y}$ the reservation policy of the outsider or the strong party: $\nabla^{\prime} C_{z}$ i 2 for the case of outsider control and, $\nabla^{\prime} C_{s}$ i 2 for the case of direct control. For the case of direct control when platform commitment is

possible, we further de.ne $x^{\prime} \not y+R$ to be the greatest platform, $x_{s}$, against which $S$ would not create unrest against itself after winning. ${ }^{1}(\phi$ is the measure function on the space of voters with ${ }^{1}(\mu: \mu 2[i 2 ; 2])=1$. We will prove the lemma for the no-commitment case. The proof for the commitment case is derived by replacing $y$ by $\mathrm{x}$ and $\mathrm{y}$ by $\mathrm{x}$.

(i) We ..rst prove that $r=0$ whenever $s$ wins. $s$ knows $y$ in all cases. Setting y (or x) above $\boldsymbol{y}$ leads to $r=1$ (by de. nition of $y$ ) and this gives i $c_{s}$ to $s$.

(a) Under outsider control, i $\mathrm{c}_{\mathrm{s}}<\mathrm{i} 4$ (by $\mathrm{A} 1^{0}$ ) and is s's lowest possible payox so any strategy containing $\mathrm{y}$ ( or $\mathrm{x}$ ) above $\boldsymbol{y}$ is weakly dominated by the strategy 
obtained by replacing any such policies (platforms) by $y=i 2(x=; 2)$. By assumption $A B, r=0$ for any strategy with all policies weakly less than $y$. Hence, $r=0$ when $s$ wins by assumption AA.

(b) Under direct control, i $\mathrm{C}_{\mathrm{s}}>\mathrm{i} 4$ (by A 1) but $\mathrm{s}$ can always create unrest at stage 4 so s's payox is bounded below by $i c_{s}$, even if $s$ loses. Replacing any policies (platforms) that ever lead to unrest, by $y=i 2(x=; 2)$, therefore creates a weakly dominating strategy. Hence, $r=0$ for any policy in s's strategy set by assumption AA.

Henceforth, we only use $r$ to refer to the probability of unrest when w wins. By part (i), when $s$ wins, the policy/political unrest outcome is of the form $\left(y_{s} ; 0\right)$. When $w$ wins the outcome is of the form $\left(y_{w} ; r\right)$. (For the case of platform commitment, substitute $\mathrm{x}$ for $\mathrm{y}$.)

(ii) We can now prove that $M$ is decisive by considering all 6 possible orderings of $y_{s}, y_{w}$ and 0 . To prove that $M$ is decisive, we prove that $\left.S M w\right)^{1}(\mu: s \mu w), \frac{1}{2}$ and similarly wMs $)^{1}$ ( $\mu$ : w $\left.\mu s\right), \frac{1}{2}$.

In the case with platform commitment, the voters know that $\mathrm{y}=\mathrm{x}$; so only $\mathrm{r}$ needs to be estimated and we look at deterministic policy choices. We begin with this case.

In each of the six cases (A-F), we prove that $s M w){ }^{1}(\mu: s \mu w), \frac{1}{2}$ and $\left.w M s\right)$ ${ }^{1}$ ( $\mu$ : w $\left.\mu s\right), \frac{1}{2}$ using the fact that the two sets $\mu>0$ and $\mu<0$ each constitute a measure $\frac{1}{2}$ of voters. We de.ne $\phi_{\mu}{ }^{\prime} U_{\mu}(s)$ i $U_{\mu}(w), \phi_{0}{ }^{\prime} U_{0}(s)$ i $U_{0}(w)$ and $\phi^{\prime} \phi_{\mu \mathrm{i}} \phi_{0}$. It is clear that SM w, $\phi_{0}>0$ and s $\mu \mathrm{w}, \phi_{\mu}>0$ so, for example, $\phi>0$ ) (sM w) suw).

We characterize values of $\phi_{\mu}$ and $\phi_{0}$ in cases (a-d) that will be needed in the proof: (a) $y_{s} ; y_{w} \cdot \mu$

$$
\begin{aligned}
\phi_{\mu} & =y_{s} i \mu_{i}\left(y_{w} ; \mu\right) \phi(1 ; r)+r \phi c \\
& =y_{s} i y_{w} \phi(1 ; r)+r \phi(c ; \mu):
\end{aligned}
$$

$y_{s} ; y_{w} \cdot 0$ 


$$
\phi_{0}=y_{s} i y_{w} \phi(1 ; r)+r \notin c
$$

(b) $y_{s} \cdot \mu \cdot y_{w}$

$$
\phi_{\mu}=y_{s} \mathrm{i} \mu_{\mathrm{i}}\left(\mu_{\mathrm{i}} y_{w}\right) \phi(1 ; r)+r \phi C
$$

$\mathrm{y}_{\mathrm{s}} \cdot 0 \cdot \mathrm{y}_{\mathrm{w}}$

$$
\phi_{0}=y_{s}+y_{w} \phi(1 ; r)+r \phi c
$$

(c) $\mu \cdot y_{s} ; y_{w}$

$$
\begin{aligned}
\phi_{\mu} & =\mu_{i} y_{s} i\left(\mu_{i} y_{w}\right) \phi(1 ; r)+r \phi c \\
& =i y_{s}+y_{w}(1 ; r)+r(c+\mu)
\end{aligned}
$$

$0 \cdot \mathrm{y}_{\mathrm{s}} ; \mathrm{y}_{\mathrm{w}}$

$$
\phi_{0}=i y_{s}+y_{w} \phi(1 ; r)+r \phi c
$$

(d) $y_{w} \cdot \mu \cdot y_{s}$

$$
\phi_{\mu}=\mu_{i} y_{s} i\left(y_{w} i \mu\right) \phi(1 ; r)+r \phi c
$$

$y_{w} \cdot 0 \cdot y_{s}$

$$
\phi_{0}=\mathrm{i} y_{s} \mathrm{i} y_{w} \phi(1 ; r)+r \phi c
$$

Case $A: y_{s} \cdot y_{w} \cdot 0$.

First, we verify that $\mathrm{sM} w)^{1}(\mu: \mathrm{s} \mu \mathrm{w}), \frac{1}{2}$ by showing that suw for all $\mu<0$ in this case. We investigate in turn the voting behavior of the three sets of voters, $\mu<y_{s}, y_{s} \cdot \mu \cdot y_{w}$ and $y_{w} \cdot \mu \cdot 0$.

(i) It is clear that all $\mu \cdot y_{s}$ prefer $s$ because by (5),

$$
\phi_{\mu}=i y_{s}+y_{w}(1 ; r)+\mu \phi r+r \phi c, 0
$$


since $\mathrm{i} \mathrm{y}_{\mathrm{s}}=j \mathrm{y}_{\mathrm{s}} \mathrm{j}, \mathrm{j} \mathrm{y}_{\mathrm{w}}(1 \mathrm{i} r) \mathrm{j}$ and $\mathrm{c}>4>\mu$ (ii) For $\mathrm{y}_{\mathrm{s}} \cdot \mu \cdot \mathrm{y}_{\mathrm{w}} \cdot 0$; by (3) and (2)

$$
\phi=2\left(y_{w} i \mu\right)(1 ; r) i r \mu, 0
$$

as both terms are positive .

(iii) For $\mathrm{y}_{\mathrm{s}} \cdot \mathrm{y}_{\mathrm{w}} \cdot \mu \cdot 0$ we use (1) and (2) to compute $\phi=\mathrm{i} r \mu, 0$ : Thus, $\mathrm{sM} w)^{1}(\mu: \mathrm{s} \mu \mathrm{w}), \frac{1}{2}$.

Second, wM s ) ${ }^{1}$ ( $\mu$ : w $\left.\mu s\right), \frac{1}{2}$ since all $\mu>0$ prefer $w$ whenever $M$ prefers $w$. This follows from the fact that $\phi=\mathrm{i} r \mu$ by (1) and (2) and this is clearly less than or equal to 0 for $\mu>0$. Thus, $M$ is decisive when $y_{s} \cdot y_{w} \cdot 0$.

Case $B: y_{s} \cdot 0 \cdot y_{w}$.

(i) all $\mu \cdot y_{s}$ prefer s since

$$
\phi_{\mu}=\mathrm{i} y_{s}+y_{w}(1 ; r)+\mu r+r c>0
$$

(ii) for $\mu 2\left(y_{s} ; 0\right)$, we use (3) and (4) to compute

$$
\Phi=+\mu_{i} \mu(1 ; r)=i \mu(2 ; r)>i r \mu, 0:
$$

Therefore, sM w ) ${ }^{1}(\mu: \mathrm{s} \mu \mathrm{w}), \frac{1}{2}$.

If wMs, all voters with ideal points $\mu$ such that $\mu 2\left[0 ; y_{w}\right]$ will vote for $w$, since

$$
\phi=i \mu+r \mu \cdot 0:
$$

In addition, all voters with ideal points $\mu$ such that $\mu 2\left[y_{w} ; 2\right]$ will also vote for $w$, since by (4)

$$
\Phi=\mathrm{i} 2 \mathrm{y}_{\mathrm{w}}(1 ; \mathrm{r})+\mathrm{r} \mu \cdot 0 \text { : }
$$

Therefore, wM s ) ${ }^{1}(\mu:$ w $\mu s), \frac{1}{2}$. Thus, $M$ is decisive when $y_{s} \cdot 0 \cdot y_{w}$.

Case $C: 0 \cdot y_{s} \cdot y_{w}$. 
First, if SM w, then all voters with ideal points $\mu \cdot 0$ will prefer $\mathrm{s}$ since by (5) and (6) $\phi=r \mu$, 0. Second, because $y_{s}$ is closer to the median voter's ideal point and because there is no political unrest when $y_{s}$ is implemented, wM $s$ can be ignored because it cannot arise. So, $M$ is decisive when $0 \cdot y_{s} \cdot y_{w}$.

Case $D: y_{w} \cdot y_{s} \cdot 0$

All $\mu>0$ clearly prefer $s$ since $y_{s}$ is closer to their ideal point and there is no risk of political unrest when $s$ implements $y_{s}$. This is also true for $\mu=0$ which means that both sM w and sMw. WM s never arises. So, $M$ is decisive when $y_{w} \cdot y_{s} \cdot 0$.

Case $\mathrm{E}: \mathrm{y}_{\mathrm{w}} \cdot 0 \cdot \mathrm{y}_{\mathrm{s}}$

All $\mu>y_{s}$ clearly prefer $s$ since $y_{s}$ is closed to their ideal points and never leads to political unrest. For all $\mu 2\left[0 ; y_{s}\right]$, we use (7) and (8) to compute

$$
\phi=2 \mu \mathrm{ir} \mu, 0
$$

Thus, sM w ) suw for all $\mu 2(0 ; 2]$ or ${ }^{1}(\mu: s \mu w), \frac{1}{2}$.

If wM s, all $\mu \cdot y_{w}$ prefer $w$ since $\phi_{\mu}=2 y_{w}(1 ; r)+r \mu \cdot 0$. In addition, all $\mu 2\left[y_{w} ; 0\right]$ also prefer $w$ since by $(7),(8)$

$$
\$=2 \mu \mathrm{ir} \mu \cdot \mathrm{i} r \mu \cdot 0
$$

Thus, wM s ) wus for all $\mu 2[i 2 ; 0)$ or ${ }^{1}$ ( $\mu$ : w $\left.\mu s\right), \frac{1}{2}$. Therefore, $M$ is decisive when $y_{w} \cdot 0 \cdot y_{s}$.

Case $\mathrm{F}: 0 \cdot \mathrm{y}_{\mathrm{w}} \cdot \mathrm{y}_{\mathrm{s}}$

sM w implies suw $8 \mu>0:$ First, all $\mu>y_{s}$ clearly prefer $s$ since $y_{s}$ is closer to their ideal points and there is no risk of unrest when $s$ implements $y_{s}$. Second, all $\mu 2\left[y_{w} ; y_{s}\right]$ also vote for $s$ since by $(7),(6)$

$$
\phi=\left(2 \mu_{i} 2 y_{w}\right)(1 ; r)+r \mu, 0:
$$


Finally, all $\mu 2\left[0 ; y_{w}\right]$ also prefer s since by (5), (6)

$$
\varnothing=r \mu, 0 .
$$

Conversely, if wM s, then all $\mu \cdot 0$ prefer $w$ since by (5), (6)

$$
\phi=r \mu \cdot 0:
$$

Thus, $M$ is decisive when $0 \cdot y_{w} \cdot y_{s}$.

In the case without platform commitment, voters may now have non-trivial uncertainty over $y_{w}$ but we assumed common beliefs. Furthermore, $y_{s}=i 2$ so we only have to treat cases $A$ and $B$, without the subcases $A(i)$ and $B(i)$. Taking the expectation of $\phi$ over the remaining subcases, for $\mu, 0$ and $\mu$. 0 in turn, veri..es that $M$ is decisive exactly as before. This completes the proof that $M$ is decisive.

\section{Proof of Proposition 1}

When $\mathrm{s}$ wins, $\mathrm{s}$ chooses its ideal point, $\mathrm{y}=\mathrm{i} 2$ : $\mathrm{w}$ never causes unrest. When $\mathrm{w}$ wins, $w$ always seeks to avoid political unrest because $c_{w}, 4$. Therefore, $y_{w} \cdot y$ and since $w$ gains by increasing $y_{w}$ on the range $[i 2 ; y)$, the equilibrium must have $y_{w}=y$ and $r(y)=0$. With $r(y)=0$, w prevents unrest by implementing exactly y. All voters with $\mu>\frac{\nabla i 2}{2}$ prefer $w$. Since $\nabla=c_{s} i 2<2$ by $A 1$, this includes all voters with $\mu, 0$, and hence at least $50 \%$ of the electorate so $w$ wins. (We could have used Lemma 1 here, but we wrote out the above proof to show that $c_{\mu}$ is irrelevant.) This is the unique SPE.

\section{Proof of Proposition 2}

First, we show by contradiction that $r\left(c_{w}\right)$ is decreasing in $c_{w}$ : Let $c_{w}^{0}$ and $c_{w}$ be two levels of the cost unrest to the weak party such that $c_{w}^{0}<c_{w}$. De..ne by $r^{0} r\left(c_{w}^{0}\right)$ and $r^{\prime} r\left(c_{w}\right)$ : De..ne also by $y_{w}^{0}=y\left(c_{w}^{0}\right)$ and $y_{w}=y\left(c_{w}\right)$ : We have,

$$
{ }^{f} U^{i} y_{w}^{0} ; c_{w}{ }^{\phi} i U\left(y_{w} ; c_{w}\right)^{\alpha} i^{f} U^{i} y_{w}^{0} ; c_{w}^{0}{ }^{\phi} i U^{i} y_{w} ; c_{w} c^{\phi \alpha} \cdot 0
$$


because the ..rst bracket is non-positive by optimality of $y_{w}$ given $c_{w}$ and the second bracket is non-negative by optimality of $\mathrm{y}_{\mathrm{w}}^{0}$ given $\mathrm{c}_{\mathrm{w}}^{0}$. But, after substituting and simplifying, the right hand side equals,

$$
{ }^{i} c_{w} \text { i } c_{w}^{0}{ }^{\phi f} r\left(y_{w}\right) \text { i } r^{i} y_{w}^{0}{ }^{\phi \alpha}={ }^{i} c_{w} \text { i } c_{w}^{0}{ }^{\phi i} r i r^{d+} \cdot 0
$$

Since $c_{w}^{0}<c_{w} ;(9)$ implies that $r^{0}>r$. This means that $r^{\pi}$ is a decreasing (step) function of $c_{w}$. ( $r^{\star x}$ is a step function since $r^{\not} 2 f 0 ; p ; 1 g$ ):

(ii) $c_{w} ; \epsilon_{5}$ (respectively, $\epsilon_{z}$ for outsider control case) determine $r$, the risk of disruption when $w$ wins the election. When $s$ wins, $r=0$. Note that $r$ is independent of $c_{0}$ : When $r=0$ there is nothing to prove. When $r>0$, we will now show that $r^{e}$ is a step function which shifts down from $r$ to 0 at a critical level of $c_{0}, b_{0}$. In the Subgame Perfect Equilibrium, $M$ is decisive and chooses between $\left(y_{s} ; r_{s}\right)=(i 2 ; 0)$ and $\left(y_{w} ; r_{w}\right)=\left(y_{w} ; r\right)$. When $s$ wins $(i=s), M$ has payox $i 2$ and $r^{e}=0$. When $w$ wins $(i=w), M$ has payox $U_{0}\left(y_{w} ; r\right)=i j y_{w} j(1 ; r) ; r \$ c_{0}$. If $r>0, \frac{@_{0}\left(y_{w} ; r\right)}{œ_{0}}=i r<0$ while $u_{0}(s)$ is independent of $c_{0}$. Hence, $M$ may prefer $w$ for low values of $c_{0}$ but whenever $r>0, M$ prefers $s$ for suф ciently high values of $c_{0}$ and the shift in preference occurs at some value $c_{0} 2[2 ; 1)$. This proves that when $r>0$ there exists,

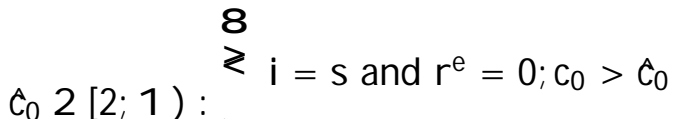

$$
\begin{aligned}
& ? i=w \text { and } r^{e}=r ; c_{0}<c_{0}
\end{aligned}
$$

In particular, $r^{\mathrm{e}}$ declines as $\mathrm{c}_{0}$ rises and $\mathrm{r}^{\mathrm{e}}=0$ as $\left.\mathrm{c}_{0}, \mathrm{c}_{0}\right)$.

\section{Proof of Proposition 4}

In proving lemma 1, we showed that s never causes $r>0$ so $\sup X_{s} \cdot y$. Similarly, if $w$ oxers a platform to the right of $y, w$ knows that if it wins it gets its lowest possible payou of $\mathrm{i} \mathrm{C}_{\mathrm{w}}$. By deviating to platform $y$, it does strictly better if it ever wins (as R $>0$ and $y$ is the best policy it can hope for) and it can do no worse (since $\left.i(2 ; \quad y), \quad i C_{w}\right)$. Thus $\sup X_{w} \cdot \mathbb{y}$. U sing these two implications of assumption 
AA (that weakly dominated strategies are avoided), we separate the proof into two cases.

In order to rule out uninteresting knife edge equilibria in which one party never wins (equally ruled out by trembling hand perfection arguments), we assume that voters mix between $s$ and $w$ when indixerent (Assumption $A C$ )

Case $\left.y \cdot 0: \sup X_{s} \cdot y^{\prime}\right)$ w's best response is $y$ because against $x_{s}<y$, this uniquely gives $w$ its highest possible payo given the threat, while against $x_{s}=y$ the policy cannot be improved for $w$ and no deviation could increase w's chance of winning. If $w$ can never win we must have $X_{s}=f y g$ and $\left.1 / 4 y ; y\right)=1$ (s cannot oxer any policy closer to 0 than $\forall$ either) but this contradicts assumption AC. Since $w$ can win, $X_{w}=f y g$. The only best response for $s$ in turn is also $y$ unless $\left.1 / 4 y ; y\right)=0$ in which case $\mathrm{s}$ is willing to oxer any platform. We designed $A C$ to ensure that $1 / 4(y ; y) \in 0$. Using $A C$, we have a unique best responses of $\&$ so that there is a unique equilibrium with convergence of platforms at $\Psi$. Without using $A C$, there would simply be an additional range of equilibria in which only $w$ wins and $s$ adopts any strategy it likes or only $\mathrm{s}$ wins and $\mathrm{w}$ randomizes over strategies (which must have signi..cant weight on $\boldsymbol{y}$ ). In these equilibria, the winner always oxers $y$ so the policy outcome is still at the "convergence point," $y$.

Case $y>0$ : Given that all strategies use only platforms $x \cdot y$, the problem reduces to platform competition on the restricted policy space, $[i 2 ; y]$ and where the extra dimension created by the risk of unrest can be neglected since no party ever oxers a platform with $r>0$. The median voter's ideal point, 0 , lies strictly inside this range and we can apply the well known median convergence theorem - see Roemer [1994] for a proof which treats a case in which parties are ideological but also value winning the election for its own sake and therefore encompasses our model.

\section{Proof of Proposition 5}

We assume that $\mathrm{s}$ always knows $y$ and so, exactly as in the proof of proposition 4, undominatedness (assumption $A A$ ) requires that $\sup X_{1} \cdot a$ and $\sup X_{2} \cdot b$, 
meanwhile, $w$ only knows that $y \cdot b$, so we can only know that, $\sup X_{w} \cdot b$ any platform above bguarantees $w$ its lowest payo when it wins and is weakly dominated by oxering $b$ which gives $w$ the highest payox it can hope for when it wins. Thus assumption $A A$ gives $\sup X_{w} \cdot b$ and $\sup X_{1} \cdot a$ while $\sup X_{2} \cdot b$ We now derive further restrictions on equilibrium form.

1. Suppose $s$ pools on a single platform, $x$. Then $x \cdot$ a else $s_{1}$ will never choose $x$. Furthermore, ${ }^{\prime}(x)=p$ since voters learn nothing. We now consider what w's responses can give: (i) if $X_{w}=b$ then $w$ wins because $p<\hat{p}$ by $A 4$ implies that,

$$
p\left(i c_{0}\right)+(1 ; \quad p) b>i \hat{p} \phi c_{0}+(1 ; \quad \hat{p}) b=b_{i} \quad\left(b_{i} a\right)=a, x
$$

and so $w$ gets a payox of $U_{w}^{\prime}$ i $p \$ c_{w}+(1 ; p)(b ; 2+R)$; (ii) if $x_{w}<x$ then $s$ wins $\left(r=0\right.$ either way) and so $w_{3}$ gets a payos of $u_{w}^{0} x^{\prime} x_{i} 2 \cdot a_{i} 2$. Now $p<\hat{p}, c_{W}+a_{i_{3}} 2>0$ and since $\frac{c_{0} 2}{b+2} \cdot \frac{c_{0}+a}{b_{i} a}=\frac{1}{\hat{p}} i 1$, A 5 guarantees that $c_{w} \cdot c_{0}+2+R \frac{1}{\bar{p}} ; 1$ so,

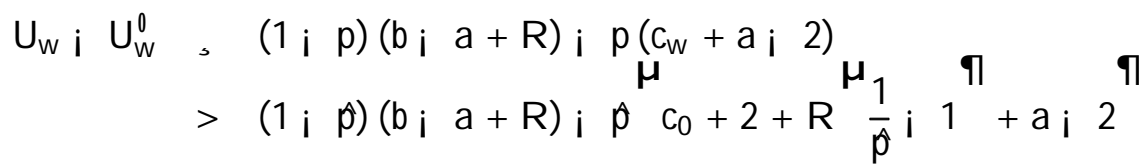

$$
\begin{aligned}
& =b_{i} a_{i} \hat{p}\left(b+c_{0}\right)=0
\end{aligned}
$$

(iii) For $\mathrm{x}<\mathrm{a}, \mathrm{x}_{\mathrm{w}} 2\left[\mathrm{x} ; \mathrm{a}\right.$ ) is dominated by $\mathrm{x}_{\mathrm{w}}=\mathrm{a}$ as $\mathrm{R}+\mathrm{a}_{\mathrm{i}} 2>\mathrm{x}_{\mathrm{i}} 2$ (when $\mathrm{x}=\mathrm{a}$, [ $x$; $a)$ is empty); (iv) For $x_{w} 2(a ; b)$, w gets a convex combination of $U_{w} i\left(b_{i} x_{w}\right)$ and $U_{w}^{0}$ both of which are worse than $U_{w}$ so that would be a dominated response.

It follows that w's best response is restricted to $x_{w} 2 \mathrm{fa}$; bg. Now if $x_{w}=a$ with probability 1 then, either $1 / 4(x ; a)<1$ in which case $s_{2}$ would deviate to $a+$ " or $1 / 4 x ; a)=1$ but then $w$ would deviate to bto get $u_{w}$ which is greater than $a_{i} 2$. So we must have $\mathrm{b} 2 \mathrm{X}_{\mathrm{w}}$.

Suppose that $x_{w}=b$ with probability 1 and $1 / 4(b, b)>0$. Then $s_{2}$ would deviate to b to increase its payox by $1 / 4(b ; b) R$. There is a set of equilibria in which $X_{w}=f b g$, $X_{s}=f x g($ with $x \cdot a)$ and $\left.1 / 4 b ; b\right)=0$. In these equilibria, $w$ always wins but the platforms must exhibit divergence of at least $b_{i}$ a so we store this result. 
2. Now we must study non-singleton strategies for $s$. We begin with a corollary of the above: $w$ cannot always lose: an equilibrium in which $w$ always loses would have to have pure pooling (if $\mathrm{X}_{1}\left[\mathrm{X}_{2}\right.$ contained more than one platform we can derive a contradiction because both types of s would strictly prefer oxering, and winning on, the more extreme of any two such platforms) but the above argument proved that $\mathrm{w}$ must always win in any pure pooling equilibrium.

3. We can show that w's best response lies in $f a ; b g$ in any PBE. We de.ne $X_{\mathrm{w}}^{\text {? }}$ to be the set of $X_{w} 2 X_{w}$ for which $w$ wins with strictly positive probability in the hypothesized PBE. We know that $X_{w}^{?} \in$; , the null set, because $w$ cannot always lose.

For $x_{w} 2 X_{w}^{?} \backslash[; 2 ; a)$, we want to consider a deviation to $x_{w}=a$. We have to consider the consequences of the deviation for all possible $x_{s} 2 X_{s}$ (of course, some of the cases may not arise) and integrate using the weights in s's strategy to compare the expected return to $x_{w}$ with that from the deviation: (i) A gainst $x_{s}>a$, w loses both at $x_{w}$ and at the suggested deviation (s's platform will be closer to 0 given that $x_{s}$. b and $s$ wins because $s$ never causes unrest by Lemma $1(i)$ ). (ii) A gainst those $x_{s}<a$ to which $w$ was losing at $x_{w}, w$ will win by deviating because $r=0$ when $x_{w}=a$ and jaj $<j x_{s} j$, this gives a "bene.t gain" of $R$ and a "policy gain" of $a_{i} x_{s}$. (iii) A gainst those $x_{s}<a$ at which $w$ was winning at $x_{w}, w$ still wins and has a policy gain of $a_{i} x_{s}$. (iv) A gainst $x_{s}=a, w$ would have been losing and a deviation to $a$ implies no policy change and possibly some bene.t gain. Now by the de. nition of $\mathrm{X}_{\mathrm{w}}^{?}$, we know that $\mathrm{w}$ must have been winning sometimes so the expectation places positive weight on case (iii) where $\mathrm{x}_{\mathrm{w}}=\mathrm{a}$ brings a strict improvement and since this deviation causes no losses in the other cases, it is strictly optimal for $w$ to deviate. This contradiction proves that $X_{w} \backslash[i 2 ; a)=$;

With a little more dic culty, we can also prove that $X_{w}^{?} \backslash(a ; b)=;$. Take $x_{w} 2$ $X_{w}^{?} \backslash(a ; b)$ and consider the deviation to $x_{w}=b$. (i) A gainst $x_{s} 2(a ; b),{ }^{\prime}=0$ and $w$ wins at $b$ with a policy gain of $b_{i} x_{s}$ (and bene.t gain of $R$ if $w$ was losing). (ii) A gainst $x_{s}=b$, w was losing and may now win $R$ with no policy change. (iii) A gainst 
those $x_{s}$ - a to which $w$ was losing, either $w$ continues to lose or w now wins at $b$ and the key question is whether $w$ wants to start winning. To answer this, note that w only starts winning if ' $\left(x_{s}\right)=$ ' satis..es

$$
\begin{gathered}
x_{s}<{ }^{\prime}\left(i c_{0}\right)+\left(1 i^{\prime}\right) b \\
)<\frac{b_{i} x_{s}}{b+c_{0}}
\end{gathered}
$$

Using assumption A 5 to substitute for $c_{w}$,

$$
\begin{aligned}
& \text { ' }\left(\text { i } c_{w}\right)_{3}+(1 ; \quad)\left(b_{3} i \quad 2+R\right), i \quad\left(x_{s} \text { i } 2\right) \\
& >\frac{\left(b_{i} x_{s}\right) \text { i } c_{0} i 2 i \frac{c_{0} i}{b+2} R+\left(c_{0}+x_{s}\right)\left(b_{i} 2+R\right) i\left(x_{s} \text { i } 2\right)\left(b+c_{0}\right)}{3,} \\
& =\frac{i \frac{c_{0 i} 2}{b+2} b+x_{s} 1+\frac{c_{0} 2}{b+2}+c_{0}}{3, b+c_{0}} \phi R \text {, which, noting that } x_{s}, i 2 \text {, } \\
& \frac{\frac{c_{0} i 2}{b+2}\left(i b_{i} 2\right)+\left(c_{0} i 2\right)}{b+c_{0}} \phi R=0
\end{aligned}
$$

from which we see that w only starts to win when w is strictly better ox by winning. (iv) Against those $x_{s} \cdot a$ at which w was winning, w makes a policy gain of $b_{i} x_{s}$. A gain, we have that the deviation never hurts and because case (iii) cannot be the only case, we know that w strictly gains from the deviation. This contradiction proves that $X_{w}^{?} \backslash(a ; b)=$;

4. Combining the results, we have; $6 X_{w}^{?} \mu$ fa; bg. Now if b $2 X_{w}^{?}, w$ is strictly better ox at $b$ than at any platform at which $w$ is sure to lose (b $2 X_{w}, 9 x_{s}$ : $\mathrm{x}_{\mathrm{s}}<{ }^{\prime}\left(\mathrm{i}_{\mathrm{c}}\right)+\left(1 \mathrm{i}{ }^{\prime}\right) \mathrm{b}$ and part (iii) of the last argument proved that $\mathrm{w}$ strictly bene.ts from winning here for all $x_{s}$ against which it wins). Meanwhile, if a $2 x_{w}$ ? $\mathrm{w}$ is strictly better ox at a than at any platform at which w always loses because, for all $x_{s}$ at which $w$ wins, $x_{s}<{ }^{\prime}\left(i c_{0}\right)+\left(1 ;{ }^{\prime}\right)$ a and from this we can use the fact that,

$$
\text { A5) } c_{w}<c_{0}+2+{\frac{c_{0} i}{a+2}}^{\text {ๆ }} R
$$

to repeat the argument of case (iii) above, substituting a for $b$ throughout. This proves that $X_{w}=X_{w}^{?} \mu f a ; b g$. 
5. Suppose that $w$ mixes with probability weight $q$ on $a$ and $1 \mathrm{i} q$ on $b$, for some q $2[0 ; 1]$

(i) If $q=0$ then we have divergence of at least $b_{i} a$ a fraction at least $p$ of the time because $x_{s}$ 'a whenever $s=s_{1}$. Next, we de.ne $q^{\prime} \frac{R+b+2}{2 R+b+2}$ which lies strictly between 0 and 1 for any $R>0$. If $0<q$. $q$ then $1 ; q, \frac{R}{2 R+b+2}$ and we have divergence of at least $b_{i}$ a a fraction at least $\frac{R}{2 R+b+2} \phi$ of the time. If $q>q$, we must treat two cases.

(ii) If $q>\boldsymbol{q}$ and $1 / 4 a ; a)=1$ then we must have some $s$ sometimes oxer a platform with $\mathrm{x}<\mathrm{a}$ else $\mathrm{w}$ would always be losing at $\mathrm{a}$, contradicting the result in point 4 above. But either type of $\mathrm{s}$ can get a payox bounded below by,

$$
q(i 2 ; a+R)+(1 ; q)(; 2 ; b)
$$

by adopting platform a. While an upper bound to the payo available from a platform to the left of $a$ is,

$$
q(i 2 i a)+(1 ; q)(i 2+2+R)
$$

and this is strictly lower than the lower bound given $q>$ q:

$$
\left.q>\frac{R+b+2}{2 R+b+2}\right) \quad q \phi R+(1 ; q)\left(; b_{i} 2 ; R\right)>0
$$

(iii) If $q>q$ and $1 / 4 a ; a)<1$ then $s_{2}$ has no best response $e^{22}$ unless it is $b s_{2}{ }^{\prime} s$ best response cannot lie in $(a ; b)$ because ' $(x)=0$ for all $x$ in this range and $w$ only oxers $a$ or b so moving closer to a would always increase $s_{2}$ 's payox; furthermore, $\mathrm{s}_{2}$ 's best response cannot lie in $\left[i 2 ; a\right.$ ) because $s_{2}$ would lose to $w$ when $w$ oxers a as above and deviating to $\mathrm{a}+$ " for suф ciently small " arbitrarily closely approximates the same lower bound payox as in (11) above, so we have the same result. Finally, $\mathrm{s}_{2}$ 's best response cannot equal a because $\mathrm{s}_{2}$ does strictly better (a gain within "of

\footnotetext{
${ }^{22}$ If the policy space is discrete, $s_{2}$ could have a best response just to the right of a (at " $a^{+}$") and $s_{1}$ could be setting a platform of a but in this case $w$ oxers $b$ because $w$ then wins against $s_{2}$ and not against $s_{1}$, implying that $w$ gains $b_{i} a^{+}$with probability $1_{i} p$ and $R$ with probability $1_{\text {i }} p_{\text {i }} p \$^{1 / 4} /(a ; a)$ which is unambiguously positive if $p \cdot \frac{1}{2}$.
} 
$\left.R \phi^{1 / 4}(a ; a)\right)$ by deviating to $a+"$. Hence, $s_{2}$ 's best response is b as claimed. So we have divergence of at least $b_{i}$ a with probability at least $(1 ; q) p+q(1 ; p)$ of the time (note that $(1 ; q) p+q(1 ; p), \min (p ; 1 ; p)$, for all $q)$.

Putting the results together, we have divergence of at least $b_{i}$ a a fraction no less than $\min \mathrm{p} \oiint_{\frac{\mathrm{R}}{2 \mathrm{R}+\mathrm{b}+2}} ; 1 \mathrm{i} \mathrm{p}$ of the time. In conclusion, we have a strictly positive lower bound on the occurrence of divergence for any $R>0$.

HARVARD UNIVERSITY

YALE UNIVERSITY

\section{REFERENCES}

Alesina, Alberto, “Credibility and Policy Convergence in a T wo-Party System with Rational Voters," American Economic Review, LXXVIII (1988), 796-806.

Alesina, Alberto, and Howard Rosenthal, Partisan Politics, Divided Government and the Economy, (New York, Cambridge University Press, 1995).

Calvert, Randall, "R obustness of the Multidimensional Voting M odel: Candidates' motivations, Uncertainty, and Convergence," A merican J ournal of Political Science, XXIX (1985), 69-95.

Butler David and Dennis K avanagh, The British General Elections of February 1974 (The Macmillan Press Ltd., 1974).

Dorfman, Gerald Allen, Government Versus Trade Unionism in British Politics Since 1968 (Stanford, Calif. : Hoover Institution Press, 1979).

Ellman, Matthew and Leonard Wantchekon, "Electoral Competition Under the Threat of Political Unrest", M imeo, Yale University, 1999.

Instituto Universitario de Opinión Pública, Los Salvadoreños y las Elecciones de 1994, (San Salvador: UCA, 1994). 
Montgomery, Tommie Sue, Revolution in El Salvador, From Civil Strife to Civil Peace (B oulder Westview Press, 1995).

Moses, J onathan W. "A bdication from National Policy A utonomy: What's Left to Leave?" Politics \& Society XXII (1994), 125(44).

Roemer, J ohn E. "A Theory of Dixerentiated Politics in a Single-Issue Framework," Social Choice and W elfare, XI (1994), 355-380.

Shepsle, K enneth A., M odels of Multiparty Electoral Competition (New York : Harwood A cademic Publishers, 1991).

Stahler-Sholk, Richard, "EI Salvador's Negotiated Transition, From Low Intensity Conłict to Low Intensity Democracy," J ournal of Interamerican Studies and World A aairs, XXXVI (1995), 1-53.

Vickers, George and J ack Spence, "Elections: the Right Consolidates Power," NA CLA Report of the Americas, XXVIII (1994), 1-15.

Wantchekon, Leonard, "Strategic Voting in Conditions of Political Instability: the 1994 Elections in El Salvador," Comparative Political Studies, XXII (1999), 811-835.

Wantchekon, Leonard and David Lam, "Electoral Competition Under a Red Shadow: The Exects of Chinese Military Threats on the 1996 Elections in Taiwan," Working Paper 96-02, I.S.P.S. Yale U niversity, 1996. 
Figure I:

Equilibrium Probability of Unrest as a Function of $c_{w}$.

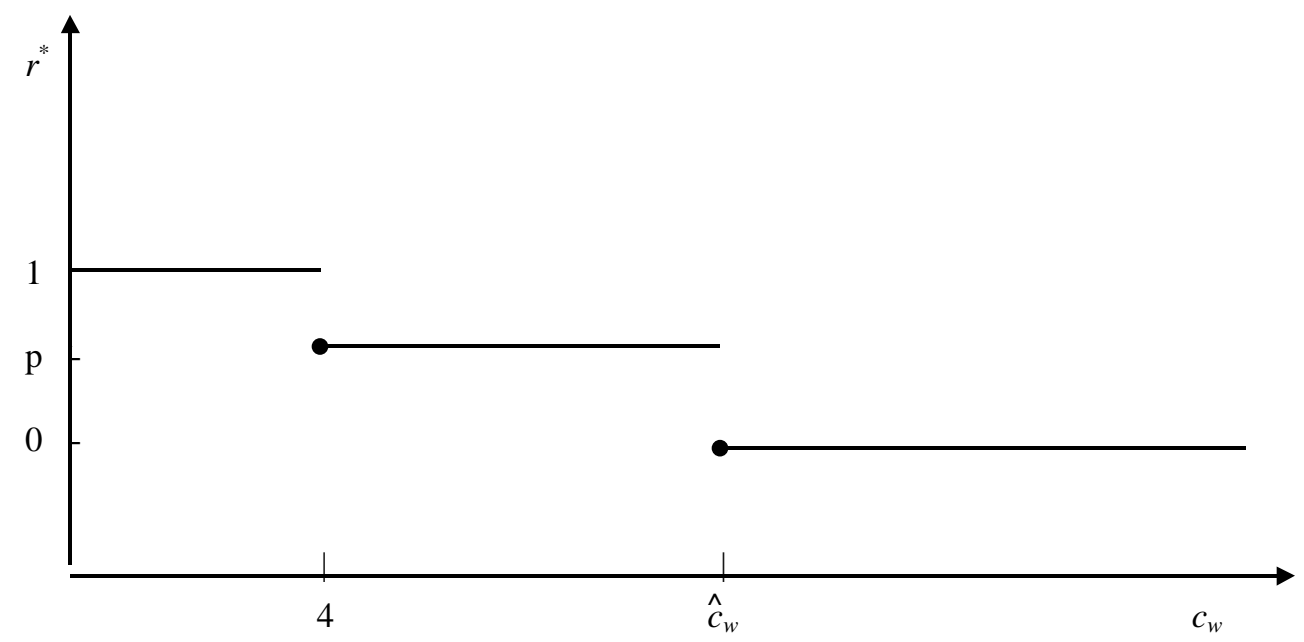


TABLE I:

Summary of the Main Results.

\begin{tabular}{|c|c|c|}
\hline & Complete Information & Private Information \\
\hline & 2 the weak party wins the election: & $\begin{array}{l}2 \text { when } \mathrm{c}_{0} \text { is "moderate", the weak } \\
\text { party wins, implements a "moderate" } \\
\text { policy and there is a risk of unrest. }\end{array}$ \\
\hline No Commitment & $\begin{array}{l}\text { "moderate" and "safe" policy, } \mathrm{y} \text { : } \\
2 \text { there is no political unrest }\end{array}$ & $\begin{array}{l}2 \text { when } c_{0} \text { is "high", the strong party } \\
\text { wins, implements an "extremist" } \\
\text { policy and there is no unrest. }\end{array}$ \\
\hline
\end{tabular}

\begin{tabular}{|c|c|c|}
\hline Commitment & $\begin{array}{l}{ }^{2} \text { both parties choose the same } \\
\text { platform. } \\
{ }^{2} \text { the strong party wins if it } \\
\text { directly controls the source of } \\
\text { the threat. } \\
{ }^{2} \text { there is no political unrest. }\end{array}$ & $\begin{array}{l}2 \text { when } c_{w} \text { and } p \text { are "moderate", the } \\
\text { strong party and the weak party } \\
\text { choose dixerent platforms, either } \\
\text { party wins and there is a risk } \\
\text { of unrest. } \\
2 \text { when either } c_{w} \text { or p is "high", both } \\
\text { parties choose the same platform, } \\
\text { the strong party wins and there } \\
\text { is no unrest. }\end{array}$ \\
\hline
\end{tabular}

Note: (1) 8 is the reservation policy of the strong party, that is, the minimal policy compromise that weak party must make to prevent political unrest, (2) $c_{0}$ is the cost of unrest to the median voter, (3) $c_{w}$ is the cost of unrest to the weak party, (4) p is the probability that the strong party is "very" strong. 
